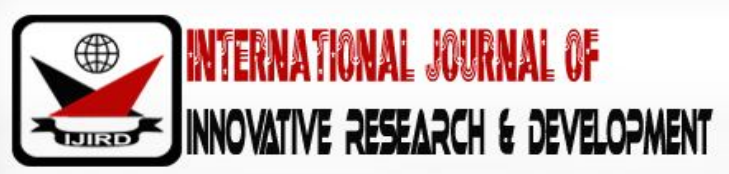

ISSN 2278 - 0211 (Online)

\section{Assessment of Hands-on Activities on Students' Achievement and Attitudes towards Chemical Bonding}

\begin{tabular}{c} 
Twumasi A. K. \\
$\begin{array}{c}\text { Department of Chemistry Education, university of Education, Winneba, Ghana } \\
\text { Hanson R. } \\
\text { Department of Chemistry Education, university of Education, Winneba, Ghana }\end{array}$ \\
\hline
\end{tabular}

\begin{abstract}
:
The study assessed the efficacy of hands-on activities on students' academic achievement and attitude in learning ionic and covalent bonds in a senior high and a technical school in Ghana. The sample size for the study was 30 and comprised of 22 males and 8 females who were purposively sampled for the study. The main instruments used to collect data were tests, interviews and questionnaire. The various hands-on activities employed included writing Lewis dot structures, drawing diagrams for ionic bonds and covalent bonds, tug of war, modelling with ball and sticks as well as calculation of electro negativity differences. Statistical analyses showed that students scored significantly higher scores $(t=-6.32 ; p<0.05)$ in the post-test than in the pre-test. Also, a gain of 3.83 was obtained for the post test over the mean score of the pre-test. This confirmed that the treatment strategy significantly improved students' performance in learning chemical bonding through the interactive hands-on activities. The study also revealed that hands-on learning increased students' interest to read chemistry, facilitated understanding and recall of chemical concepts, made lesson more exciting and led to positive motivational outcomes. Furthermore, the activities engaged students, made them critical thinkers, and enhanced their learning skills.
\end{abstract}

Key words: Academic achievement, covalent bond, hands-on activities, ionic bond

\section{Introduction}

The overall importance of education in general and science education in particular, to mankind cannot be overemphasized. No nation can afford to neglect science education at any level of education and hope to thrive in any field of human endeavour. Science education is imperative for useful living in any society. It is at the center for producing resources necessary for socio-economic, scientific and technological development. Training young scientists require knowledgeable, dedicated and resourceful science teachers to help lay good scientific foundations in their lives. The importance of science has enabled governments to design policies to increase science learning in schools. Unfortunately, despite government's drive to draw more students to science, especially at the second cycle levels, many students keep running away from it (Eminah, 2007).

O'Connor (2002) identified the use of inappropriate teaching methods as one of the factors that contribute to the low participation and performance of students in science. The teaching methods used are not practical enough, and that teachers make little effort to relate the concepts learnt and their examples or illustrations to real life situations, especially within the context of the students' own lives and environment. This has a negative effect on students' interest and motivation to study science, technology, engineering and mathematics (STEM) subjects. Danso (2010) indicated that teachers favour teachercentred, knowledge-based teaching methods that leave little room for learners' participation. The most commonly used teaching methods at both basic and secondary levels have been found to be lecturing, question and answer, explanations of procedures, and notes giving, in that order (O'Connor, 2002).

In school science teaching, ideas need to be presented in ways that are both authentic representations of the scientific concepts, and yet simple enough to be meaningfully understood by the learners. The teaching of chemistry in high schools requires the development of more effective and scientifically aligned strategies to teach the key concepts of chemical bonding. According to Teichert and Stacy (2002), this attempt is motivated by many worldwide studies that reveal that the traditional approach of teaching bonding is problematic. More specifically, during the last two decades, researchers have found that students lack a deep conceptual understanding of the key concepts regarding chemical bonding and so failed to integrate mental models of them into a coherent conceptual framework (Bodner \& Domin, 1998; Taber 2001). 
Hanson (2017a) stated in her study that teacher trainees were confused about the concepts of covalent and ionic bonds. She reported that some of the teacher trainees conceptualised sodium and chlorine atoms as being held together by covalent bonds. Others intimated that sodium chloride existed as molecules which were held together in a solid form by covalent bonds. If these misconceptions are not corrected then there is a high probability of teachers imparting them to students. Similarly, Coll and Taylor (2010) found from their study that students have misconceptions and learning difficulties concerning atomic structure, chemical bonding and matter. Hanson (2017b) further asserted that chemical bonding continues to cause difficulties for learners regardless of the fact that it is taught at junior secondary school (age 12-14) and senior secondary school (age 14+ to 17+). Thus, more teaching approaches which will make students perform activities for which they will form their own authentic scientific ideas and be responsible for them were suggested as a way out by Hanson.

According to Ekwueme, Ekon and Ezenwa-Nebife (2015), the hands-on-approach is a method of instruction where students are guided to gain knowledge by experience. This means giving the students the opportunity to manipulate the objects they are studying, for instance, plants, insects, rocks, water, magnetic field, scientific instruments, calculators, rulers, mathematical set, and shapes. In fact, it is a process of doing mathematics and science through active participation in the classroom. A review of literature showed that hands-on activities help students to outperform students who follow traditional, text-based programmes (Turpin, 2000), if they should begin studies from a common intellectual cognition or entry point. Hands-on activities enhance students' understanding and replace their misconceptions with scientific conceptions (Ünal, 2008). It develops students' attitudes toward science positively and encourages their creativity in problem solving (Bilgin, 2006). Furthermore, it promotes their independence, and improves skills such as reading, arithmetic computation, and communication. Lebuffe (1994) emphasized that children learn better when they can touch, feel, measure, manipulate, draw, and make charts, record data and find answers for themselves rather than being given the answer in a textbook or lecture.

Ekwueme, Ekon and Ezenwa-Nebife (2015) again posit that the hands-on learning approach is learner-centered and involves the child in a total learning experience which enhances his ability to think critically. It is obvious therefore, that any teaching strategy that is skewed towards this direction can be seen as an activity-oriented teaching method. Through the hands-on-approach, students are able to engage in real life illustrations and observe the effects of changes in different variables. It offers concrete illustrations of concepts and improves students' academic achievement in learning. Obanya (2012), in his convocation lecture confirmed the above statement by adding that the average retention rate of learning by lecture is $5 \%$ while that of practice by doing is about $75 \%$. It can be seen that retention rate increases progressively with the use of more interactive and activity-oriented teaching methods. Ekwueme and Meremikwu (2010) observed in their study that some teachers object to the use of interactive activity-oriented method stating that it is time consuming and do not permit total coverage of the syllabus.

Hands-on activities sometimes make use of real objects to support multiple modes of communication, and link visual learning to what is said and discussed (Lee, Penfield \& Maerten-Rivera, 2009). They enable students to discuss debate, verbalize and explain processes and concepts while working together. An observation made on hands-on learning showed that students demonstrated strong communication skills and positive attitude towards learning (Bass, Yumol, \&Hazer, 2011). Bass, Yumol and Hazer (2011) opined that with the right kind of planning and presentation, hands-on teaching can restore focus and spark engagement. An independent observation of teachers using hands-on learning revealed that students were enthusiastic and generally stayed on-task during guided hands-on activities. In order for the students to learn the abstract concepts in chemical bonding, they must make models or analogies, aside from doing laboratory tasks. In this way, students will have the potential of enhancing their understanding in chemical bonding (Gabel, 2003).

Chemical bonding is a central concept in chemistry and therefore a thorough understanding of it is essential for understanding almost every other topic in chemistry such as carbon compounds, proteins, polymers, acids and bases, chemical energy, and thermodynamics (Hurst, 2002). According to Robinson (2003), chemical bonding is considered by teachers, students, and chemists to be a very complicated concept. The concepts associated with chemical bonding such as covalent bonds, molecules, ions, giant lattices, and hydrogen bonds and their structural representations are abstract. In order to understand these concepts, students must be familiar with mathematical and physical concepts that are associated with the bonding concept such as orbitals, electronegativity, and polarity. Studies show that many students in Ghana tend to learn science by rote and hence lack understanding of science concepts since no meaningful learning occurs (Anamuah-Mensah \& Benneh, 2010; Jones, 2008). This might be due to the teaching methodology employed. Also, the quality of science teaching and learning in basic, senior high schools and tertiary institutions in Ghana has been criticized by parents, science educators, technocrats and the government (Anamuah-Mensah, Mereku, \& Ampiah, 2009). It is in the light of the difficulties that students face in learning important basic chemical concepts like chemical bonding that the researchers were motivated to investigate how hands-on activities could influence SHS 2 science students' academic achievement and attitudes towards the learning of chemical bonding in chemistry.

\subsection{Research Questions}

i. What impact would the use of hands-on activities have on students' attitudes towards their study of chemical bonding?

ii. To what extent would the use of hands - on activities enhance students' academic achievement? 


\section{Methodology}

\subsection{Study Design}

The study was an action research which sought to find some solutions to students' poor performance and attitudes towards chemical bonding. The sample size for the study was thirty (30) and comprised of twenty-two (22) male and eight (8) female students of a Senior High and Technical Schools in the Ashanti region. The researcher adopted a purposive sampling technique because all the members of the science class had some difficulty with chemical bonding. The main instruments used to collect data were class tests and questionnaire. A 15-minute pre-test was conducted to discover the difficulties students faced in chemical bonding while a post-test was organised after the implementation of intervention strategies which involved hands-on activities. This was supplemented with questionnaire and unstructured interview for corroboration. The 10 test items were validated by an expert (a senior Lecturer) at the Department of Chemistry Education in the University of Education, Winneba. This was done to ensure that the content and difficulty levels of the questions were suitable for testing. The test items were pre-tested on non-participating students for construct and content reliability.

\subsection{Intervention}

The intervention strategy designed to deepen students' concepts about ionic and covalent bonds through hands-on activities is outlined below.

i. Students were asked to write the following information on index cards about the first 20 elements: element symbols, atomic number, atomic mass, state of matter, and element type.

ii. Elements written on index cards were grouped as metals and non-metals.

iii. Lewis dot structures of elements and compounds were written on sheets and on index cards.

iv. Electronegativity difference between reacting or bonding elements were calculated for the justification of the polarity or otherwise of covalent bonds.

v. Model kits were used to construct compounds to enhance mental model formation (or mental images of compound) to deepen the concept of bonding.

After the treatment, ten multiple choice questions were administered. The maximum time required for the test was 15 minutes. At the end of 15 minutes, the papers were collected from the students and assessed using a prepared marking scheme. Each of the tests (pre-test and post-test, see Appendix A) consisted of 10 questions and the total score allocated was 20 marks. Students were however interviewed during the treatment period to know how far the use of hands-on activities had affected their attitudes toward the learning of chemical bonding.

\subsection{Data Analysis}

The data obtained from the study were put into frequency tables for analysis. Descriptive statistics such as mean and standard deviation as well as inferential statistics (correlation and t-test at 95\% confidence level) were computed to establish the relationship between pre-test and post-test scores. The mean gain (difference between mean score of post test and that of pretest) was also determined and used to assess their conceptual growth.

\section{Results}

A two-tailed t-test for independent sample analysis for the pretest and posttest scores is presented in Table 1 below.

\begin{tabular}{|c|c|c|c|c|c|c|c|}
\hline Test & No & mean & SD & df & r & t-value & p-Value \\
\hline Pre-test & 30 & 11.80 & 2.30 & 29 & 0.67 & -6.32 & $1.9 \times 10^{-6}$ \\
\hline Post-test & 30 & 15.63 & 2.40 & 29 & & & \\
\hline
\end{tabular}

Table 1: Two Tailed T-Test for Independent Sample Analysis for Pretest and Posttest

Scores

Table 1 shows that, the mean score obtained by students in the pre-test was $11.80(\mathrm{SD}=2.30$ ) while that of the mean score for the post test was 15.63 ( $\mathrm{SD}=2.40$ ). The small values of standard deviations obtained for the two tests indicated that most of the students scored close to the mean values. The correlation between the two test scores was moderate (0.67).

The result of students' response to the questionnaire after the intervention is presented in Table 2 below.

\begin{tabular}{|c|c|c|c|}
\hline No. & Items & Yes (\%) & No (\%) \\
\hline 1 & Did you obey the activity procedure & $28(93.3)$ & $2(6.7)$ \\
\hline 2 & Did you follow activities easily & $24(80)$ & $6(20)$ \\
\hline 3 & Did you enjoy the lesson & $27(90)$ & $3(10)$ \\
\hline 4 & Did you get the concepts of the lesson by doing the activities & $23(76.7)$ & $7(23.3)$ \\
\hline
\end{tabular}




\begin{tabular}{|c|c|c|c|}
\hline 5 & Was there student-student interaction during the lesson & $27(90)$ & $3(10)$ \\
\hline 6 & Did the teacher acts as a guide & $26(86.7)$ & $4(13.3)$ \\
\hline 7 & Did the teacher has the primary role in delivering the content & $25(83.3)$ & $5(16.7)$ \\
\hline 8 & Did the method increase your interest to read chemistry & $28(93.3)$ & $2(6.7)$ \\
\hline 9 & Can you explain your answers with confidence & $23(76.7)$ & $7(23.3)$ \\
\hline 10 & $\begin{array}{c}\text { Do you prefer activity-oriented teaching to tradition teaching without } \\
\text { activity }\end{array}$ & $25(83.3)$ & $5(16.7)$ \\
\hline
\end{tabular}

Table 2: Students Response to the Questionnaire after Intervention

Table 2 shows that $93.3 \%$ (28) of the students were able to obey the activity procedure with only $6.7 \%$ (2) having some difficulties. Also, 80\% (24) easily followed the procedure for the activities. The difficulty students had in following the activity procedure was lack of understanding of some of the key terms. Among the students, only $10 \%$ (3) did not enjoy the lesson while the remaining $90 \%$ (27) enjoyed the lesson. The fact that higher number of students enjoyed the lesson indicated that hands-on activities have the potential to increase students' interest in learning. As to whether students were able to grasp concepts by doing activities, 76.7\% (23) indicated 'yes' with only $23.3 \%$ (7) indicating 'no'. On whether hands-on teaching enhanced student to student interaction, 90\% (27) of the students indicated 'yes' while 10\% (3) indicated 'no'. Majority of the students responded that grasping of teaching concepts was enhanced through doing and interaction with colleagues. Many of them also ticked that the teacher acted as a guide during the lesson, indicating that the teacher had a primary role to deliver content. Students' interest to read chemistry increased with majority of them indicating that, they could explain their chosen answer with confidence. The students realised that their knowledge on the concepts has increased and they were much confident to explain their answers. Confidence building is important to enable students come out with their thoughts and ideas for correction. In addition, 83.3\% (25) of the students indicated their preference for hands-on teaching to traditional teaching.

\section{Discussion}

The scores obtained by students in the post-test (mean score=15.6) were higher than the pre-test scores (mean score $=11.8)$. Statistical analyses showed that students scored significantly higher $(t=-6.32 ; p<0.05)$ in the post-test than in the pre-test. The result also showed that there was a gain of 3.83 from the mean scores of the post-test and pre-test which also confirmed that the treatment had significant influence on students' performance. This overall gain can be attributed to the effectiveness of the intervention strategy employed. The present study supports the findings of Ekwueme, Ekon and EzenwaNebife (2015) that hands-on activity can improve students' performance in mathematics and basic science. Similarly, Turpin (2000) reported that learning via hands-on activities was more effective than learning by traditional method in the area of science achievement.

The results further showed that most of the respondents were able to follow hands-on activity procedure easily. This was because the researcher used simple English which was easy to read and understand. However, key terms necessary to enhance their conceptual understanding was not compromised. About $90 \%$ of the respondents indicated that they enjoyed the handson oriented teaching. Some students associated their reason to the fact that hands-on doing made the lesson real and prevent abstract teaching.

In a follow up interview some of the respondents stated that, conducting hands-on activities made lesson more exciting and led to positive motivational outcomes. This assertion confirms the findings of Franklin and Peat (2005) who concluded that hands-on learning provided a more realistic and exciting experience of the content. This suggests that through hands-on activities students are able to exhibit their knowledge and skilful abilities. Also, hands-on teaching can restore focus and spark engagement through students' reflection on lessons.

Furthermore, $76.7 \%$ (23) of the respondents understood the concepts of the lesson by engaging in activities. This means that hands-on activities have the ability to engage students, make them critical thinkers and improve their cognitive skills of learning. In an interview, a student stated that, before the intervention, he did not understand why the bond between hydrogen at the left of the periodic table and chlorine at the right side of the periodic table (i.e. $\mathrm{HCl}$ ) do not form ionic bond but forms covalent bond whereas sodium and chorine in the same locations on the periodic table do. He confessed that the confusion was solved after he determined the electronegativity differences of $\mathrm{HCl}$ and $\mathrm{NaCl}$. This indicates that, the student's misconception has been corrected to agree with scientific conception. Additionally, 90\% (27) of the respondents indicated that the hands-on doing enabled them to interact with other students during the lesson while the teacher guided them to develop concepts relevant to the lesson. Similarly, an observation of hands-on learning by Bass, Yumol and Hazer (2011) revealed that students demonstrated strong communication tied to working in teams. Team learning through hands-on activities enables good students to assist the weak students in the class thereby making the class more enjoying and interesting. Additionally, one of the respondents mentioned in an interview that, she was shy to ask his teacher question in class but had assistance from colleagues when they were put into groups to work. Some students stated that they told their questions to their team members to ask the teacher on their behalf. This suggests that students' behavioural deficiencies are being complemented upon by those who do not have such deficiencies. This subsequently ensure that higher number of students build scientific concepts with the assistance of peers and experts (Teachers). 
Majority of respondents in this study (93\%) affirmed that hands-on learning increased their interest to read chemistry. According to Hidi and Renninger (2006), interest is an important variable in the school context, as it can influence students' levels of learning, their academic performance and the quality of their learning experience. About 76.7\% of the respondents were sure that they could explain their answers with confidence while $83.3 \%$ of them indicated their preference to activityoriented teaching (hands -on doing). In the interview, respondents stated that 'hands-on doing' facilitates understanding and recall of chemical concepts. For instance, a student confirmed that writing Lewis structures as well as modeling of compounds before drawing their structures enabled her to overcome the difficulty she had in identifying multiple bonds in structures. In a similar study, Ateş and Eryilmaz, (2011) indicated that students who experienced hands-on activities frequently (every day or once a week) had significantly higher scores of sciences achievements than those students who experienced hands-on science infrequently.This assertion is confirmed by the outcome in this study, where those who were taught using the hands-on method out-performed those who studied the same topic by the traditional method by 3.83 points.

\section{Conclusion}

The hand-on activities carried out in the study were writing of chemical symbols and atomic number of elements on index card, grouping of elements into metals and non-metals, writing lewis dot structure, drawing diagrams for ionic bonds and covalent bonds, using tug of war to explain the concept of polarity, modelling with ball and sticks as well as calculation of electronegativity difference. Results gathered indicated that these activities significantly improved students' performance in the learning of ionic and covalent bonds as was found in similar studies by Gabel (2003). Again, hands-on activities made lessons more interesting, engaged students, enabled them to interact with colleagues, built their confidence, made them critical thinkers and improved their cognitive skills of learning, which led to positive motivational outcomes. This finding correlates with that by Ateş and Eryilmaz, (2011). Generally, it could be concluded that the hands-on activities enabled students in this study to demonstrate positive attitudes towards the learning of chemical bonding and made significant gains in their conceptual understanding as illustrated by high gains in post-test scores. These are further corroborated by their responses to questions posed to them in the unstructured interview sessions.

\subsection{Recommendations}

i. Hands- on teaching activities must be well planned to achieve teaching objectives at all levels of chemistry education, and especially in teaching chemical bonding.

ii. Teachers must supervise and guide students to develop concepts during lessons. It should be noted that some students are likely to play with teaching materials and might not follow the presentation of content. Thus, teacherfacilitation must be taken seriously.

\section{References}

i. Anamuah-Mensah, J., \& Benneh, B. (2010). Particular issues of teacher education in Ghana.The UNESCO Teacher Training Initiative for Sub-Saharan Africa. Accra: Ghana.

ii. Anamuah-Mensah, J., Mereku, D. K., \& Ampiah, J. G. (2009). TIMSS 2007 Ghana.Report:Findings from IEA's trends in international mathematics and science study at the eighthgrade. Accra: Adwinsa Publications (Gh) Ltd.

iii. Ateş, 0., \& Eryilmaz, A. (2011). Effectiveness of hands-on and minds-on activities on students' achievement and attitudes towards physics. Asia-Pacific Forum on Science Learning and Teaching , 12 (1), 1-22.

iv. Bass, K. M., Yumol, D., \& Hazer, J. (2011). The Effect of Raft Hands-on Activities on Student Learning, Engagement, and 21st Century Skills." RAFT Student Impact Study. Retrieved January 24 , 2012, from <http:/ / www.raft.net/ public/ pdfs/ Rockman-RAFT-Report.pdf>.

v. Bilgin, I. (2006). The effects of hands-on activities incorporating a cooperative learning approach on eight grade students' science process skills and attitudes towards science. Journal of Baltic Science Education, 1(9), 27-37.

vi. Bodner, G., \& Domin, D. (1998). Mental models: The role of representations in problem solving in chemistry. Paper presented at International Council for Association in Science Education. Summer Symposium, Proceedings.

vii. $\quad$ Coll, R. K., \& Taylor, N. (2010). "Alternative conceptions of chemical bonding held by upper secondary and tertiary students," vol. 19, no. 2,. Research in Science \& Technology Education, , 19 (2), 171-191.

viii. Danso, J. B. (2010). Evaluation of inclusive education practice in Ghana: Survey of inclusive pilot schools. Thesis submitted to the Department of Educational Foundation, Faculty of Education, University of Cape Coast, in partial fulfillment of the requirements for the award .

ix. Eminah, J. K. (2007). The alignment of J.H.S curriculum prescriptions and classroom practice. Journal of Alternative Development and Area Studies, 26(3), 73-101.

x. Ekwueme, C. O., Ekon, E., \& Ezenwa-Nebife, D. C. (2015). The Impact of Hands-On-Approach on Student Academic Performance in Basic Science and Mathematics. Higher Education Studies, 5(6), 47-51.

xi. Ekwueme, C. O., \& Meremikwu, A. (2010). The use of calculator in Teaching Calculations in logarithms in secondary schools. Journal of Issues on mathematics, 13, 117-118.

xii. Franklin, S., \& Peat, M. (2005). Virtual versus real: an argument for maintaining diversity in the learning environment. International Journal of Continuing Engineering Education and Life Long Learning , 15, 67-78. 
xiii. Gabel, D. (2003). Enhancing the Conceptual Understanding of Science. Educational Horizons 3, 70-76.

xiv. Hanson, R. (2017a). Assessing the potential of worksheets as a tool for revealing teacher trainees' conceptions about chemical bonds. Mississauga, Canada: CICE-2017 Proceedings.

xv. Hanson, R. (2017b). Unearthing Conceptions about Types of Chemical Bonding Through the Use of Tiered Worksheets - A Case Study. International Journal for Cross-Disciplinary Subjects in Education (IJCDSE , 8 (2), 3112-3122.

xvi. Hidi, S., \& Renninger, K. A. (2006). The four-phase model of interest development. Educational Psychologist , 41, 111127.

xvii. Hurst, O. (2002). How we teach molecular structure to freshmen. Journal of Chemical Education, 79(6), 763 - 764.

xviii. Jones, K. R. (2008). Will education be powerful enough to provide satisfying employment and economic stability? . Career Development: NCDA Magazine No 2.

xix. Lebuffe, J. R. (1994). Hands-on science in the elementary school. East Lansing, MI: National Center for Research on Teacher Learning (ERIC Document Reproduction Service No. ED 375003).

xx. Lee, O., Penfield, R, \& Maerten-Rivera, J. (2009). Effects of fidelity of implementation on science achievement gains among English language learners. Journal of Research in Science Teaching, 46(7), 826-859.

xxi. Obanya, P. (2012). Transformational Pedagogy in Higher Education. 26th Convocation Lecture of University of Calabar, Nigeria.

xxii. O'Oconnor J., P. (2002). Teachers are the problem in SMT, not girls. Retrieved January 9, 2009, from http:/ / www.adea.org

xxiii. Robinson, W. (2003). Chemistry problem-solving: Symbol, macro, micro, and process aspects. Journal of Chemical Education(80), 978 - 982.

xxiv. Taber, K. S. (2001). The mismatch between assumed prior knowledge and the learners' conceptions: A typology of learning impediments. Educational Studies, 2(27), 159 - 171.

xxv. Teichert, M., \& Stacy, A. (2002). Promoting understanding of chemical bonding and spontaneity through student explanation and integration of ideas. Journal of Research in Science Teaching, 6(39), 464 - 496.

xxvi. Turpin, T. J. (2000). A study of the effects of an integrated, activity-based science curriculum on student achievement, science process skills, and science attitudes. Dissertation Abstracts International, 61(11), 4329A (UMI No. AAT 9993727).

xxvii. Ünal, S. (2008). Changing students' misconceptions of floating and sinking using hands-on activities. Journal of Baltic Science Education, 7(3), 134-146.

\section{Appendix A}

Pre-Intervention Test:

Circle the correct option that completes the sentences below.

1. Hydrogen Fluoride has a (an) bond and it chemical formula is
a) covalent, $\mathrm{HF}$
b) ionic, $\mathrm{HF}$
c) covalent, $\mathrm{H}_{2} \mathrm{~F}$

2. When a $\mathrm{Cl}$ atom gains an electron, it gets a charge of
a) -1
b) +1
c) 0

3. The process of becoming an ion from an atom is called
a) ionization
b) electrolysis
c) Atom affinity

4. The chemical formula of the product formed from the reaction between $\mathrm{Mg}$ and $\mathrm{O}$ is
a) $\mathrm{MgO}_{2}$
b) $\mathrm{MgO}$
c) $\mathrm{Mg}_{2} \mathrm{O}$

5. In an ionic bond, electrons are or 

a) lost or gained
b) Shared
c) none of the above

6. In a covalent bond, electrons are
a) lost or gained
b) shared
c) none of the above

7. An atom that has lost or gained electrons becomes a (an)
a) Proton
b) electron
c) ion

8. Charged atoms are called as
a) protons
b) electrons
c) ions

9. Covalent bond is formed between atoms of
a) Metals
b) non-metals
c) metals and non-metals

10. Nhas 5 valence electrons and it is diatomic. How many covalent bonds are there in a N2 molecule?
a) Single
b) double
c) triple

\section{Appendix B}

Post Intervention Test:

Circle the correct option that completes the sentences below.

1. How is the bond in $\mathrm{F}_{2}$ different from the bond in $\mathrm{KCl}$ ?
a) $\mathrm{F}_{2}$ is covalent and $\mathrm{KCl}$ is ionic
b) $\mathrm{F}_{2}$ is ionic and $\mathrm{KCl}$ is ionic
c) $\mathrm{F}_{2}$ is ionic and $\mathrm{KCl}$ is covalent

2. Calcium Oxide is a (an) compound and the formula for Calcium Oxide is
a) covalent, $\mathrm{CaO}_{2}$
b) ionic, $\mathrm{CaO}$
c) ionic, $\mathrm{CaO}_{2}$

3. Oxygen has 6 valence electrons and it is diatomic. How many covalent bonds are there in an $\mathrm{O}_{2}$ molecule?
a) single
b) double
c) Triple

4. The bond formed when $\mathrm{Mg}$ combines with $\mathrm{O}$ is
a) ionic
b) covalent 
c) metallic

5. Non-metals tend to electrons to become ions.
a) lose, positive
b) gain, negative
c) lose, neutral

6. Metals tend to electrons to become ions.
a) lose, positive
b) gain, negative
c) lose, neutral

7. Magnesium Bromide is a (an) compound.
a) metallic
b) covalent
c) ionic

8. Write the chemical formula for a compound that has one Calcium atom and 2 Chlorine atoms. Predict the bond between them.
a) $\mathrm{CaCl}_{2}$, ionic
b) $\mathrm{CaCl}_{2}$, covalent
c) $\mathrm{Ca}_{2} \mathrm{Cl}$, ionic

9. Ionic bond is formed between atoms of and
a) metals and non-metals
b) Metals
c) non-metals

10. From the list of elements given, select 2 elements that would likely form an ionic bond.
a) $\mathrm{K}, \mathrm{Br}$
b) $\mathrm{Ar}, \mathrm{C}$
c) $\mathrm{K}, \mathrm{Ar}$ 